\title{
El alcance de la Regulación Privada Transnacional: el caso de la multinacional Monsanto en Argentina
}

\section{The scope of Transnational Private Regulation: The case study of the Multinational Monsanto in Argentina}

\author{
German Ezequiel Ricci \\ Investigador independiente (Argentina) \\ ORCID: https://orcid.org/0000-0003-4359-5553 \\ ger_Ricci18@hotmail.com
}

\begin{abstract}
NOTA BIOGRÁFICA
German Ezequiel Ricci es licenciado en sociología en UCES, cuenta con un posgrado en Desarrollo Local Territorial y Economía Social en FLACSO, un Diplomado superior en Liderazgo y es Magister en Políticas públicas en la Universidad de Sydney. Actualmente se desempeña como asistente de Proyectos en OIM Argentina. Principales líneas de investigación: Gobernanza internacional, relaciones internacionales, sociología, América Latina, FMI.
\end{abstract}

\section{RESUMEN}

Este artículo analiza la Regulación Privada Transnacional (RPT) a partir de la experiencia de la multinacional Monsanto en la Argentina, desde la crisis de 2001 hasta la venta de la Compañía en 2016, desde el estructuralismo constructivista de Pierre Bourdieu. El estudio de caso se centra en las interacciones de la corporación con los agentes reguladores en el campo nacional y el campo público global, considerando las consecuencias del uso extensivo de glifosato en la salud humana. El presente estudio evidencia que los actores emergentes en el campo público global no han sido suficientes para llevar a cabo las tareas de control y legislación propias del gobierno. En cambio, las instancias estatales siguieron siendo legítimas para la regulación corporativa, aunque el modelo basado en el consenso de los commodities precisó de controles laxos. Por último, se analizan los programas de responsabilidad social corporativa implementados por Monsanto y se advierte el impacto de estos sobre el capital simbólico del Estado-Nación. Se concluye que, en el marco de la RPT, el Estado Nacional argentino le ha habilitado a la corporación la construcción de sentido para reproducir el ingreso de divisas y hacer frente a las obligaciones financieras, tanto en el campo nacional como en el campo internacional.

\section{PALABRAS CLAVE}

Regulación Privada Transnacional; consenso de los commodities; estructuralismo constructivista; neoectractivismo.

\footnotetext{
ABSTRACT

This article analyzes the Transnational Private Regulation (RPT) based on the experience of the multinational Monsanto in Argentina, from the crisis of 2001 to the sale of the Company in 2016, from the constructivist structuralism of Pierre Bourdieu. The case study focuses on the corporation's interactions with regulatory agents in the national arena and the global public arena, considering the consequences of the extensive use of glyphosate on human health. Emerging actors in the global public field have not been enough to carry out the government's own regulatory and control tasks. On the other hand, state bodies continued to be legitimate for corporate regulation, although the model based on the consensus
} 
of commodities required lax controls. Finally, the corporate social responsibility programs implemented by Monsanto are analyzed and their impact on the symbolic capital of the Nation-State. It is concluded that, within the framework of the RPT, the Argentine National State has empowered the corporation to construction of meaning in order to reproduce the income of foreign currency and face financial obligations, both in the national field and in the international field.

\section{KEYWORDS}

Transnational Private Regulation; commodities consensus; constructivist structuralism; neoextractivism.

\section{SUMARIO}

1. INTRODUCCIÓN. 2. MARCO TEÓRICO: TEORIZANDO LA EMERGENCIA DE LA GOBERNANZA TRANSNACIONAL PRIVADA DESDE EL ESTRUCTURALISMO CONSTRUCTIVISTA. 3. METODOLOGÍA. 4. LA CORPORACIÓN MONSANTO EN ARGENTINA. 4.1. LA SOJA: PRODUCTO CLAVE EN LA RECUPERACIÓN ECONÓMICA ARGENTINA. 4.1.1. La endeble regulación corporativa en el campo nacional y las reacciones simbólicas en el campo público global. 4.1.2. De lo nacional a lo regional: Las coincidencias del Mercosur con el Estado-Nación argentino en la escasa regulación corporativa. 4.1.3. Los programas de responsabilidad social y el poder simbólico. CONCLUSIÓN. REFERENCIAS BIBLIOGRÁFICAS.

\section{INTRODUCCIÓN}

Este artículo analiza la Regulación Privada Transnacional (RPT) a partir de un estudio de caso basado en la participación de la corporación Monsanto en la Argentina desde el año 2001 hasta la venta de la Multinacional en 2016, desde el estructuralismo constructivista de Pierre Bourdieu.

En los últimos años, ha habido un interés creciente en el ámbito de las políticas públicas por el nuevo paradigma de gestión de la RPT. Este tipo de marco regulatorio que surgió en el contexto de la globalización se define como un:

nuevo cuerpo de normas, prácticas y procedimientos creados por actores privados, firmas, organizaciones no gubernamentales, expertos independientes creadores de estándares técnicos y comunidades epistémicas, que desarrollan un poder regulatorio autónomo o desarrollan poderes que han sido delegados por el derecho internacional o por la legislación nacional (Cafaggi, 2014, pp. 186-187).

En la RPT emergen nuevos actores que generan una autorregulación y un autogobierno -sin autoridad formal- que involucra y afecta a la sociedad civil y que reemplazan las tradicionales actividades de control y legislación del Estado Nación y del derecho internacional, en donde la autoridad estaba circunscripta a los gobiernos nacionales que presentaban estructuras jerárquicas claramente definidas (Bell y Hindmoor, 2009; Rosenau y Czempiel, 1992).

El devenir de la RPT ha sido posible a partir de una serie de factores contextuales. Por un lado, fue necesario el desarrollo de las comunicaciones y la revolución de la información, que hizo posible la interacción e intercambio entre los actores emergentes. De esta forma, fue posible que se establezcan relaciones entre distintos agentes a nivel mundial, en forma de constelación.

Por otro lado, esta nueva estrategia de regulación y control emerge con fuerzas durante el neoliberalismo, un orden que se caracteriza por la desregulación económica, el libre mercado y una desconfianza hacia la regulación pública. La delegación de las distintas instancias de la administración estatal para la regulación de las actividades económicas -que no implica la ausencia del Estado (Graz y Nölke, 2012)- se dio paralelamente con la emergencia de nuevos actores legítimos de la sociedad civil en el mundo occidental, que se manifestaron a través de las conocidas Organizaciones sin Fines de Lucro. Sin embargo, como veremos en este artículo, en Argentina la RPT ha estado presente incluso en el estado pos-neoliberal, a partir de la crisis del 2001, momento en el que el Estado asume nuevas responsabilidades y en donde la redistribución y la inequidad constituyen la agenda de gobierno (Grugel y Riggirozzi, 2012).

La RPT ha recibido numerosas críticas en relación con sus déficits democráticos (Alberada Vivó, 2009). Varios autores han cuestionado la legitimidad de estas alianzas al señalar que tanto el acceso a la participación como el poder de decisión dentro de las mismas es limitado. Esto responde a que la conformación de alianzas 
GAPP. Nueva Época - N. ${ }^{2}$ 28, marzo 2022 - ISSN: 1989-8991 - DOI: https://doi.org/10.24965/gapp.i28.10931 - [Págs. 127-142]

El alcance de la Regulación Privada Transnacional: el caso de la multinacional Monsanto en Argentina

German Ezequiel Ricci

es voluntaria y por lo tanto discrecional ya que no todos los actores globales están igualmente representados. De hecho, las organizaciones del hemisferio sur no suelen estar igualmente incluídas que sus pares del norte, lo que socava la posibilidad de defender los intereses de ciertos sectores. Por otro lado, se cuestiona que el poder de los actores dentro de las alianzas es asimétrico, porque las corporaciones transnacionales son las que dominan las relaciones mientras que los representantes de la sociedad civil ocupan un lugar relegado ya que no participan en el proceso de toma de decisiones (Bexell et al., 2010). A su vez, esta incapacidad para influir en el proceso de toma de decisión se refleja también en la falta de mecanismos de las ONG para monitorear y hacer cumplir las regulaciones de las distintas actividades. En cuanto a las limitaciones espaciales, la TPG se apoya en esquemas de integración regional que les dan soporte a los acuerdos cooperativos y en muchos casos, al no estar del todo desarrollados, se dificulta la implementación de esta estrategia. Por último, las críticas también se han centrado en las limitaciones normativas para responder a los problemas sociales, pese a la implementación de los programas de responsabilidad social corporativa (Graz y Nölke, 2012).

El estudio de caso del presente artículo analiza el uso extensivo de glifosato (conocido comercialmente como Round Up Ready) de la corporación Monsanto que se utiliza para intensificar la producción de soja. Desde finales del siglo pasado, Argentina orientó la producción agrícola hacia este cultivo dado el elevado precio internacional (Bianchi y Szpak, 2017). Esta estrategia económica orientada al mercado internacional contribuyó a su recuperación económica tras la crisis de 2001 (Zarrilli, 2016; Rapoport, 2010), a la vez que implicó una tendencia hacia la reprimarización económica, al consolidar el fenómeno conocido como «el consenso de las commodities» (Svampa, 2013).

Si bien esta práctica conllevó ciertos beneficios económicos, fue cuestionada por sus diversas consecuencias. En cuanto al impacto ambiental, el modelo sojero provocó una deforestación masiva, una tendencia al monocultivo que rompe con el equilibrio del ecosistema y provocó la degradación de la tierra (Montenegro et al., 2005; Aizen et al., 2009). En cuanto a la distribución de la propiedad, la producción de soja implicó un nuevo tipo de organización territorial en la que se incrementó la concentración de tierras (Teubal, 2003). Este proceso conocido como «acumulación por desposesión» significó que población indígena, pequeños productores y terratenientes fueran expulsados del campo frente a la aparición de pools de siembras promovidos por capitales financieros transnacionales (Teubal et al., 2008).

Con respecto al impacto en la salud humana, varias ONG y organizaciones médicas han alertado sobre los riesgos del uso del glifosato en la población por considerarlo cancerígeno (Agosto, 2016; RALLT, 2015). De hecho, en 2019, la corporación fue condenada en Estados Unidos a partir de una demanda en la que un jubilado contrajo cáncer por manipular el producto Round up Ready (AFP, 2019). Sin embargo, en la Argentina, la falta de legislación a nivel nacional y supranacional no ha evitado que se propague su uso. Tampoco lo han impedido los actores que integran el nuevo espacio público global de la RPT.

Por lo tanto, el objetivo de investigación de este artículo consiste en analizar la regulación corporativa de los actores que integran el emergente campo público global y el tradicional campo nacional, desde la teoría de los campos de Pierre Bourdieu. Para ello, se indaga la relación entre la corporación Monsanto en Argentina y el resto de los agentes que participan en el marco de la RPT, considerando las dimensiones políticas, económicas y simbólicas, entre la crisis del 2001 y la venta de la compañía en el 2016. El enfoque sociológico adoptado permitirá centrarse en las relaciones entre diversos actores que participan simultáneamente en distintos campos y permitirá contestar ¿Cómo son las relaciones entre la corporación y el resto de los actores en el campo público global? y, por lo tanto, ¿cuál es la capacidad reguladora del nuevo campo? Por otro lado, ¿Qué posición ocupan los actores tradicionales encargados de llevar a cabo la regulación corporativa en el campo nacional y a qué obedece dicha posición?

El caso argentino evidencia la asimétrica relación de poder entre los distintos actores que intervienen en la RPT. La corporación ha desplegado distintos mecanismos para perpetuar su actividad económica pese a los efectos nocivos sobre la población. La regulación corporativa ha estado débilmente desarrollada tanto en el campo público global como en el campo nacional. A este último se recurre como una nueva instancia, tras la emergencia fallida del campo público global. En cuanto a la falta de regulación estatal en el campo nacional se sostiene que la inacción del Estado obedece a los ingresos que obtiene de la actividad agrícola a partir de su modelo productivo, que es estratégico para una estructura económica primarizada. En este sentido, el gobierno y la corporación son socios estratégicos en la explotación de recursos naturales, pendientes en la obtención de divisas, lo que le permite cumplir con sus obligaciones financieras, para un país caracterizado por las crisis económicas recurrentes (Rapoport, 2010). Por lo tanto, el modelo neoextractivista con sus consecuencias sociales y ambientales son parte del costo que el gobierno debe estar dispuesto a asumir para reproducir su modelo de acumulación (Svampa, 2018). 
Este documento está organizado de la siguiente manera: primero se expondrá el marco teórico desde el cual se analiza la experiencia de Monsanto en Argentina. Se sostiene que por tratarse de una investigación que se centra en las relaciones entre actores, la teoría de los campos de Pierre Bourdieu resulta pertinente para la misma. En segundo lugar, se especifica la metodología utilizada en el presente estudio de caso. Luego, se contextualiza a la Corporación Monsanto en Argentina, considerando las dimensiones económicas, medio ambientales, socio-territoriales y el impacto en la salud de dicha actividad. Esto servirá para comprender la relevancia de esta problemática e introducir el posterior análisis de las relaciones entre los distintos actores. Entre ellos se encuentran la capacidad regulativa de los actores en el campo público global y en el campo nacional. Por último, se aborda el poder simbólico de los programas de responsabilidad social.

\section{MARCO TEÓRICO: TEORIZANDO LA EMERGENCIA DE LA GOBERNANZA TRANSNACIONAL PRIVADA DESDE EL ESTRUCTURALISMO CONSTRUCTIVISTA}

Analizar la experiencia de Monsanto en Argentina en el contexto de la RPT requiere definir un marco teórico que contextualice el accionar de los distintos actores que participan y se ven influenciados por esta práctica. Como la RPT implica interacciones y vínculos entre distintos actores globales y locales, el desempeño de los mismos debe ser analizado por una perspectiva que se centre en las relaciones, en el posicionamiento de los actores y que permita captar las dimensiones simbólicas de cada una de ellas. Esto nos acerca a la Teoría de los Campos del estructuralismo constructivista impulsada por Pierre Bourdieu, un enfoque relacional que considera simultáneamente la estructura (parte objetivista, el campo) y la agencia (parte subjetivista, el habitus). Centra su análisis en el complejo entramado de relaciones entre actores y permite comprender sus acciones de acuerdo a la posición que ocupan en el campo social.

Según Bourdieu, el Estado detenta el monopolio de la violencia física y simbólica legítimas en el campo nacional (Bourdieu, 2015). En el marco de la RPT, las relaciones entre distintos actores se complejizan ya que las corporaciones internacionales y los actores de la sociedad civil establecen distintos tipos de alianzas y ejercen un nuevo tipo de gobernanza, por fuera del Estado nación, lo que algunos autores han llamado el nuevo espacio público global (Ruggie, 2004). Desde la teoría de los campos, en términos de Bourdieu este espacio podría denominarse campo público global, que carece de territorialización. La vinculación en este nuevo campo implica una reubicación del poder regulatorio en dos sentidos; Las responsabilidades que tradicionalmente estaban circunscriptas a la esfera Estatal en el campo nacional son delegadas a agentes privados, y a la vez que hay un pasaje del ámbito doméstico al ámbito global. Esto ha derivado en la creación de normas y reglas a nivel global que existirían por fuera del contexto nacional (Newell, 2008, p. 526).

Como el Estado nación se encuentra dotado de poder y de autoridad simbólica, y construye lo real social a partir de la nominación oficial del mundo social, hecho que le permite legitimar las relaciones de dominación (Bourdieu, 2015), es de esperar que en el nuevo paradigma estas facultades sean compartidas o cedidas a los actores del campo público global. En este sentido, la RPT implica un intento por saltearse el monopolio de la violencia física y simbólica legítima del Estado al extrapolar la construcción de sentido desde el campo nacional al campo público global.

Desde la teoría de los campos, las corporaciones participan simultáneamente en campos yuxtapuestos: En el campo nacional, como actores -principalmente- económicos, y en el campo público global como actores creadores de normas, que legitiman sus propias actividades económicas a través de un ejercicio asimétricamente compartido de regulación y control. Así, tanto las tareas como los espacios en los que participan las corporaciones se ven ampliados, lo que implica un cambio en las relaciones de poder entre distintos actores que integran el campo nacional.

La delegación de tareas que hacen los Estados nacionales a las alianzas emergentes permite que la corporación oficie simultáneamente como actor y árbitro ya que, en la RPT, las corporaciones desarrollan la autorregulación. La esperable lucha entre actores que se da dentro de los campos se traslada a la función de árbitro en la que la corporación ahora también participa. En el campo público global, la corporación integra activamente la nueva constelación de actores, influyendo en la creación y modificación de normas, en el acceso y difusión de información, y en la regulación de actividades.

Dentro de estas alianzas globales, las ONG están llamadas a monitorear el desempeño de las corporaciones ya que han adaptado mecanismos de regulación pública en el ámbito internacional (Ruggie, 2004). Los defensores de este paradigma sostienen que estas organizaciones cuentan con la capacidad de poner en la agenda pública los temas de interés local. Es decir, su principal poder se sustentaría en el capital social, 
GAPP. Nueva Época - N. ${ }^{2}$ 28, marzo 2022 - ISSN: 1989-8991 - DOI: https://doi.org/10.24965/gapp.i28.10931 - [Págs. 127-142]

El alcance de la Regulación Privada Transnacional: el caso de la multinacional Monsanto en Argentina

German Ezequiel Ricci

en términos de Bourdieu. Sin embargo, esta perspectiva desconoce tanto la discrecionalidad de esos temas como la asimétrica relación de poder con la corporación. En relación al primer punto, los intereses que motivan a la participación de los sujetos en las organizaciones de la sociedad civil dependen de los intereses que haya en ese campo, por lo que el grado de involucramiento y representación estará sesgado (Cutler, 2003; Alberada Vivó, 2009).

Respecto a las relaciones de poder, como las alianzas son de carácter voluntario y carecen de reglas para la participación, finalmente se constituyen constelaciones que son el resultado de las relaciones de poder y las luchas de ese campo (Falkner, 2003; Graz y Nölke, 2012). Por lo tanto, como la posición en el campo responde a la posesión de capital económico, político y simbólico de cada agente, las corporaciones transnacionales alcanzan una posición privilegiada respecto al resto de los representantes de la sociedad civil (Bexell et al., 2010). Además de la poca influencia sobre la corporación, debe mencionarse que la falta de herramientas de monitore conspira contra ella. Esto puede ser más evidente en contextos de pobreza en los países emergentes.

Si bien puede haber casos en los que los actores de la sociedad civil participes de las alianzas detecten el incumplimiento de las reglas acordadas, estos, a diferencia de los mecanismos tradicionales, estarán imposibilitados de ejercer penalizaciones contra la corporación. Las sanciones son de carácter simbólico y el incumplimiento de lo dispuesto solo tiene consecuencias en la reputación. Sin embargo, este daño puede ser contestado: Si el poder de presión de las ONG se apoya únicamente en la comunicación global, contrarrestar esta práctica dependerá de la mayor o menor injerencia que logre la corporación en la agenda global. El auspicio de medios masivos es uno de las tantas estrategias en la que las empresas pueden utilizar tanto para mejorar su reputación como para inhibir voces críticas.

Por todo esto, el emergente campo público global institucionaliza las asimétricas relaciones de poder de los distintos actores ya existentes en el campo nacional. La asimétrica relación de poder y la precaria capacidad de los actores para ejercer la regulación corporativa amplía el margen de maniobra de las corporaciones. De legitimarse el nuevo campo público global emergente de la RPT, la corporación podrá ejercer su violencia simbólica, logrando sumisiones que no serán percibidas como tales, transformando así las relaciones de dominación y de sumisión en relaciones legitimas (Bourdieu y Passeron, 2001).

Como actor que participa dentro del campo nacional, pero que nunca desconoce que su procedencia no lo es, la corporación se apoya sobre su poder desterritorial. Esto implica que, para el resto de los actores, la identificación de la corporación y la de sus responsabilidades se complejiza. En su carácter de huésped extranjero, la corporación transnacional siempre cuenta con la posibilidad de salirse del campo nacional o salirse y volver a entrar bajo otra forma u otro aspecto, hecho que la diferencia y fortalece respecto a los actores locales. El cambio de titulares, la venta de la compañía a otra corporación o un «refresh» institucional que incluyan programas de responsabilidad social son ejemplos de estrategias que permiten no solo disuadir las luchas dentro de determinado campo sino también contrarrestar el desprestigio y, por lo tanto, la pérdida de capital simbólico.

Para el estudio de caso de este artículo, el capital simbólico de la corporación Monsanto no solo se funda en la creencia sobre la efectividad del producto que la misma tiene para ofrecer en el campo nacional. Es también en su carácter de agente extraterritorial de donde deviene su legitimidad como actor. Su alcance global reviste de prestigio a la corporación, a partir de una creencia basada en que su eficacia le ha permitido exceder sus fronteras de origen. Esta lógica es aún más penetrante al tratarse de corporaciones cuyos capitales de origen pertenecen a las principales economías del mundo y que aterrizan en economías emergentes.

Como actor local cuyo origen proviene de otro campo es esperable que la corporación no reconozca -y, por lo tanto, no legitime- el capital simbólico del campo nacional del mismo modo que el resto de los actores locales. La falta de un sentido de pertenencia desecha cualquier tipo de nacionalismo o sentimiento patriótico que podría emerger en un campo cuyos actores comparten una identidad común y una creencia sobre esa identidad, pese a las ya conocidas dificultades que presenta el mundo contemporáneo para ello (Bauman, 2015). Si además se tiene en cuenta la mencionada posibilidad latente con la que cuenta la corporación internacional de salirse del campo nacional frente a cualquier conflicto o eventualidad, existen menos razones para que la corporación ajuste su compromiso al sentido local. Esto hace que sea esperable que la corporación desarrolle relaciones y acciones más ajustadas a los propósitos que implicaron su llegada a ese campo, es decir a sus propósitos económicos.

Con respecto a las políticas sociales, la RPT descansa en la responsabilidad corporativa de las corporaciones. Como el poder simbólico, entendido como poder de constituir lo dado por la enunciación de hacer ver y hacer cree, de confirmar o transformar la visión del mundo (Bourdieu, 2006), el desarrollo de políticas 
públicas por parte de la corporación implica también la producción y reproducción de poder simbólico, que ya no estará ajustado a los intereses del Estado -amparado en la voluntad popular-, sino a los propios intereses corporativos.

Por último, cabe mencionar algunas particularidades del campo nacional donde se sitúa el presente estudio. El Estado-Nación argentino encuentra la reproducción de capital económico a partir de las divisas obtenidas por la exportación primaria. El boom de los commodities -particularmente de la soja- a principios del siglo XXI coincidió con un cambio político significativo, en donde el Estado volvió a ocupar un lugar central, lo que implicó una redefinición de la relación entre el Estado y la sociedad. La crisis económica, política e institucional del 2001, marcó el alejamiento del paradigma neoliberal asociado al Consenso de Washington. El Estado post-neoliberal que emergió trajo consigo objetivos de redistribución económica, pero su financiamiento fue posible por el alto precio de los commodities que alentaron el modelo agroexportador (Giraudo, 2021). En este sentido, la elite política se apoyó en el «Consenso de las Commodities» que fue central para su reproducción, es decir, reproducir de su capital económico, político y por lo tanto simbólico. Este tipo de modelo presenta ciertos riesgos, por la propia lógica financiera que, inmiscuída en la actividad agrícola ha incrementado la volatilidad de precios y por lo tanto, la previsibilidad a largo plazo (Rossi, 2013; Teubal et al., 2008).

En pos de la persecución y reproducción de esos capitales, es de esperar que el Estado reproduzca esa lógica económica y esto podría implicarle establecer ciertas alianzas con otros actores que contribuyan a legitimar su posición en el campo. Esto toma una trascendental importancia si se considera la particular historia económica argentina y sus crisis económicas recurrentes, lo que exige a las elites gobernantes la permanente búsqueda de acrecentar los ingresos del Estado (Rapoport, 2010).

\section{METODOLOGÍA}

Para analizar los límites de la RPT a partir del estudio de caso de la corporación Monsanto en Argentina, este artículo presenta un análisis descriptivo, recurriendo a una interpretación conceptual del conjunto de datos, ajustado al marco teórico de Pierre Bourdieu. Se emplean métodos de investigación cualitativa, utilizando como fuentes otras investigaciones científicas, datos oficiales, artículos de periódicos e informes públicos, y estadísticas descriptivas. En primer lugar, la utilización de otras investigaciones científicas que abordan la RPT advierten a este artículo sobre las problemáticas existentes en relación al nuevo paradigma. En segundo lugar, los datos oficiales de los actores que participan de esta investigación expresados a través de sus propios medios de comunicación, como las webs oficiales, permitirán conocer en profundidad el alcance discursivo (y simbólico) de la temática en los diversos actores. En tercer lugar, las crónicas periodísticas serán utilizadas para recrear los acontecimientos locales en relación a la experiencia con el glifosato. Por último, los informes públicos y los datos cuantitativos oficiales servirán para analizar las consecuencias de las experiencias de Monsanto en el Marco de la RPT.

\section{LA CORPORACIÓN MONSANTO EN ARGENTINA}

Monsanto, originada en 1901, ingresó a Argentina en 1956, dedicándose a la producción de plásticos. Fue a partir de 1978 que su actividad se direccionó hacía la producción de agroquímicos y biotecnología, destinados a la agricultura. En las últimas décadas intensificó la ingeniería genética de semillas y produjo numerosos herbicidas, entre ellos el glifosato, comercializado bajo la marca Roundup Ready. En el año 2001, la patente de Monsanto sobre el glifosato venció, por lo que la empresa creó semillas genéticamente modificadas para ser tolerantes al glifosato (Pedemonte Castro, 2017). Para el año 2012, Monsanto manejaba el $80 \%$ del mercado de las plantas transgénicas a nivel global, con gran participación en Latinoamérica (Montenegro, 2012). El boom de los precios por las materias primas durante la primera década del siglo XXI provocó que los países de la región (principalmente Argentina, Paraguay y Brasil) adoptasen una estrategia de cultivo basada en los designios del mercado internacional, es decir en el «consenso de las commodities» (Svampa, 2013, pp. 30-45).

En el marco de la TPG, en el año 2009, Monsanto se unió a «Global Compact», que es una iniciativa voluntaria de sostenibilidad y ciudadanía corporativa que nace de una secretaría de la ONU. Actualmente, esta iniciativa es la más grande del mundo, con más de 1700 empresas adheridas y ONG transnacionales, y 
GAPP. Nueva Época - N. ${ }^{2}$ 28, marzo 2022 - ISSN: 1989-8991 - DOI: https://doi.org/10.24965/gapp.i28.10931 - [Págs. 127-142]

El alcance de la Regulación Privada Transnacional: el caso de la multinacional Monsanto en Argentina

German Ezequiel Ricci

promueve diez principios para hacer negocios. De este modo, la alianza con presencia en el campo público global que a la vez incluye actores en el campo nacional, regularía la actividad corporativa.

En los últimos años, la corporación ha sido cuestionada por distintas organizaciones de la sociedad civil por los efectos nocivos que producen sus productos. Numerosos estudios han señalado que el glifosato genera malformaciones durante el desarrollo embrionario de los vertebrados y a su vez, se ha registrado un aumento significativo de casos cáncer y malformaciones en zonas donde este producto se ha aplicado de manera masiva (Bravo y Naranjo, 2016, p. 237; RALLT, 2015). La Corporación ha sido ampliamente repudiada, alcanzado altos niveles de desprestigio.

Mientras que en el campo público global la peligrosidad sigue siendo discutida según las iniciativas que emergen en el campo nacional, en el año 2019 Monsanto fue condenada por segunda vez por negligencia en los Estados Unidos porque un jubilado contrajo cáncer al manipular este producto en su jardín. Por su parte, la Unión Europea comenzó a cuestionar el uso del glifosato, aunque finalmente lo autorizó hasta 2022, mientras que algunos Estados como Alemania, Francia y Luxemburgo han prohibido su uso (RFI, 2019; El país, 2017; Argüelles Ramos, 2020; Menéndez, 2020). En 2016, Monsanto fue comprada por la empresa Bayer, que ha decidido destinar 11.000 millones de dólares para contestar a los 125.000 demandantes en Estados Unidos por casos de cáncer (Burger y Bellon, 2020). La compra de Bayer, una empresa que se encuentra posicionada positivamente en la sociedad (Cosentino, 2019), ha permitido perpetuar la utilización del glifosato pese a sus consecuencias en la salud humana. En Argentina, la utilización de este producto sigue siendo permitida, aunque algunas instancias municipales han regulado su uso.

\subsection{La Soja: producto clave en la recuperación económica argentina}

A principios del siglo XXI, Argentina experimentó una crisis política, económica, social e institucional sin precedentes después de una década de paridad cambiaria, conocida como el Plan de la Convertibilidad. A los altos niveles de deuda pública, pobreza y desempleo se sumaba un descrédito generalizado de la elite gobernante. En ese entonces, la crisis económica argentina fue seguida de una fuerte devaluación que provocó que sus productos exportables, principalmente las materias primas, pasaran a ser atractivos en el mercado internacional por su bajo costo. En esta nueva etapa, la región latinoamericana en general -y Argentina en particular- experimentó un cambio político significativo, en donde el Estado volvió a ocupar un lugar central, lo que implicó una redefinición de la relación entre el Estado y la sociedad y que le permitió recobrar legitimidad tras la pérdida de credibilidad experimentada a comienzo del siglo. Esto significó un alejamiento del paradigma neoliberal asociado al Consenso de Washington que había marcado la política económica argentina durante los 90. El Estado post-neoliberal que emergió trajo consigo objetivos de redistribución económica (Giraudo, 2021).

Paralelamente, la demanda del cultivo de soja creció como consecuencia del aumento del precio de los commodities internacionales para alimentar masivamente al ganado de la Comunidad Europea y China, y para proveer de biocombustibles a sus vehículos. Esto estimuló la producción local y provocó que Argentina pasara a ser el tercer productor de soja y el mayor exportador de aceite y harina de soja del mundo.

En este contexto, la soja ha sido un producto clave para la recuperación económica y política del país, ya que le permitió al gobierno aumentar sus recursos fiscales -dado que la tributación de este producto exportable está centralizada en el Estado Nacional- (Giraudo, 2021). Esto hizo que el gobierno cuente con recursos para financiar políticas públicas (como por ejemplo el programa Plan jefes y jefas de Hogares Desocupados o la Asignación Universal por Hijo), que tuvo un impacto positivo en la disminución de la pobreza y la inequidad y a la vez, le permitió al Estado hacer frente a las obligaciones financieras internacionales (Bianchi y Szpak, 2017; Rapoport, 2010).

La «sojización» de la argentina se había profundizado a mediados de la década de los 90 a partir de innovaciones tecnológicas que coexistieron con la desregulación del Estado. En cuanto a las primeras, se adoptó la siembra directa -que reemplazó los ciclos de rotación con la ganadería- y el uso de soja transgénica resistente a los herbicidas a partir de 1995 (FAO, 2004, p. 7). Fue así que el uso extensivo de glifosato permitió expandir el cultivo de soja en zonas no aptas y además acelerar la producción, pese a la resistencia local (Vía Campesina, 2011). Para ello, fue necesario que unos años antes se eliminaran todas las juntas reguladoras de la actividad agropecuaria, que operaban en Argentina desde el 30. Desde entonces, el agro argentino pasó a ser uno de los más desregulados del mundo. El interés por el modelo sojero era tal que el gobierno intentó sin éxito llevar a cabo una reforma tributaria en el 2008 para aumentar las retenciones a las exportaciones de soja con el objetivo de incrementar sus ingresos, frente a las altas y volátiles cotizaciones de la soja en el mercado internacional (Teubal et al, 2008). 
En cuanto al glifosato Round Up Ready de la Corporación Monsanto, este había sido aprobado en 1995 por la Secretaría Agropecuaria de la Nación Argentina, al considerar que, en términos de bioseguridad, no había riesgos en su comercialización. Sin embargo, desde que comenzó a utilizarse de manera masiva, las críticas se han centrado en la falta de mecanismos para monitorear los efectos del uso continuo de este producto en la salud humana. La aprobación del glifosato solo consideró las dosis letales, pero no tuvo en cuenta el impacto de las pequeñas dosis de forma crónica (Montenegro, 2012). Fue a partir del daño visible que el glifosato fue generando sobre las comunidades locales que estas reaccionaron y se organizaron para realizar distintos relevamientos.

En cuanto a la regulación internacional, el glifosato fue primero incluido en la Clase Toxicológica IV, dentro de los «productos que normalmente no ofrecen peligro» (Montenegro, 2012, p. 3). Pocos años después, la Agencia Internacional para la Investigación del Cáncer de la OMS lo catalogó como «probable producto cancerígeno para el ser humano» (Bravo y Naranjo, 2016).

Mientras en el campo público global continúa la discusión sobre la peligrosidad del glifosato a partir de las iniciativas locales que cuestionan su uso, Argentina se consolidó como el país con mayor cantidad de plaguicidas por habitante por año. El escalado aumento se dio, no solo como consecuencia de la profundización del modelo sojero sino también por la resistencia que las distintas especies desarrollaron al glifosato, lo que implicó intensificar su uso. El consumo de glifosato pasó de 3 litros por hectárea a principios del siglo, a 15 litros promedio en el año 2018 (Noticiauno, 2020). En el marco del «Consenso de las commodities», se observa una fuerte correlación positiva entre el precio internacional de la soja y la cantidad de herbicida (y plaguicida) utilizado y la superficie sembrada en la Argentina entre 1991 y 2019 . En todos los casos, la correlación es igual o mayor a 0,75 (ver gráficos 1,2 y 3).

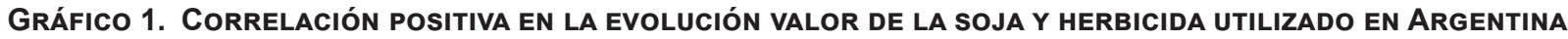

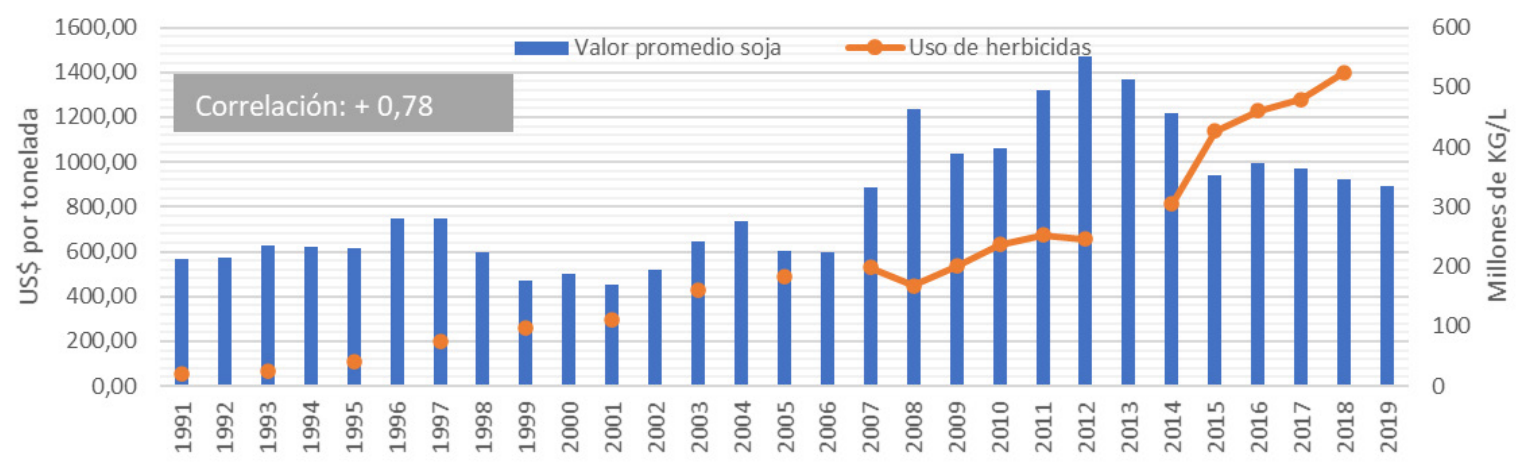

Fuente: Elaboración propia a partir de la combinación de datos disponibles en CIAFA (https://www.ciafa.org.ar/info-fertilizantesmercado) e Investing (https://es.investing.com/commodities/us-soybeans-historical-data).

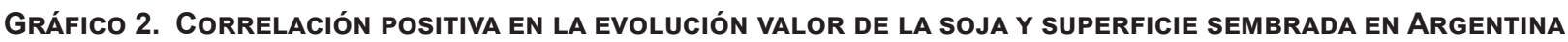

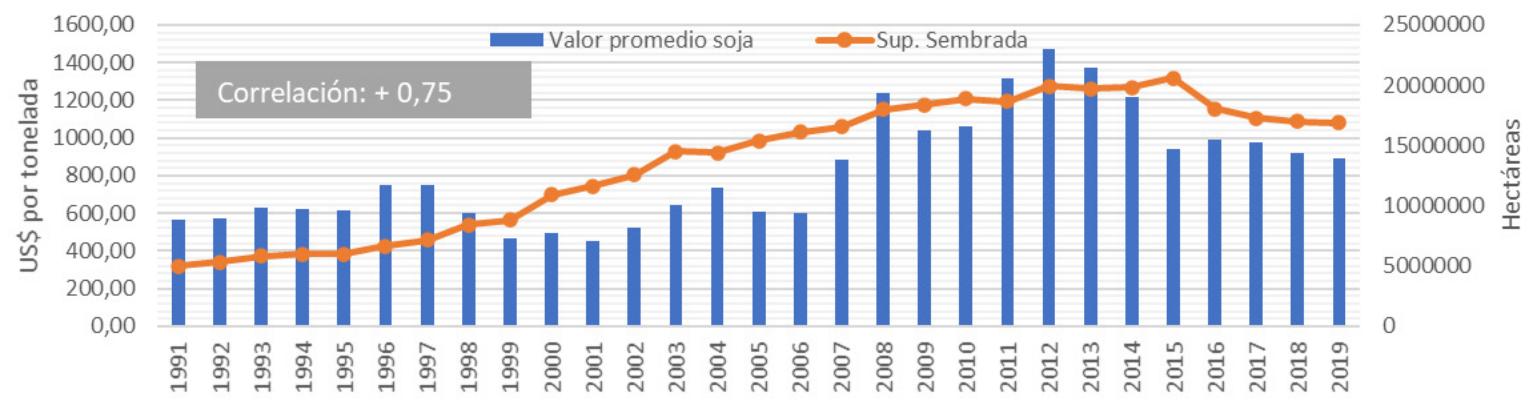

Fuente: Elaboración propia a partir de la combinación de datos disponibles el Ministerio de Agroindustria, Ganadería y Pesca (https://datos.agroindustria.gob.ar/) e Investing (https://es.investing.com/commodities/us-soybeans-historical-data). 


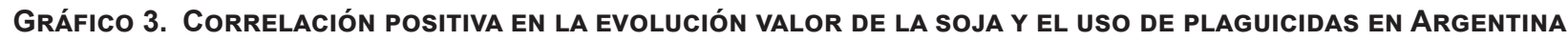

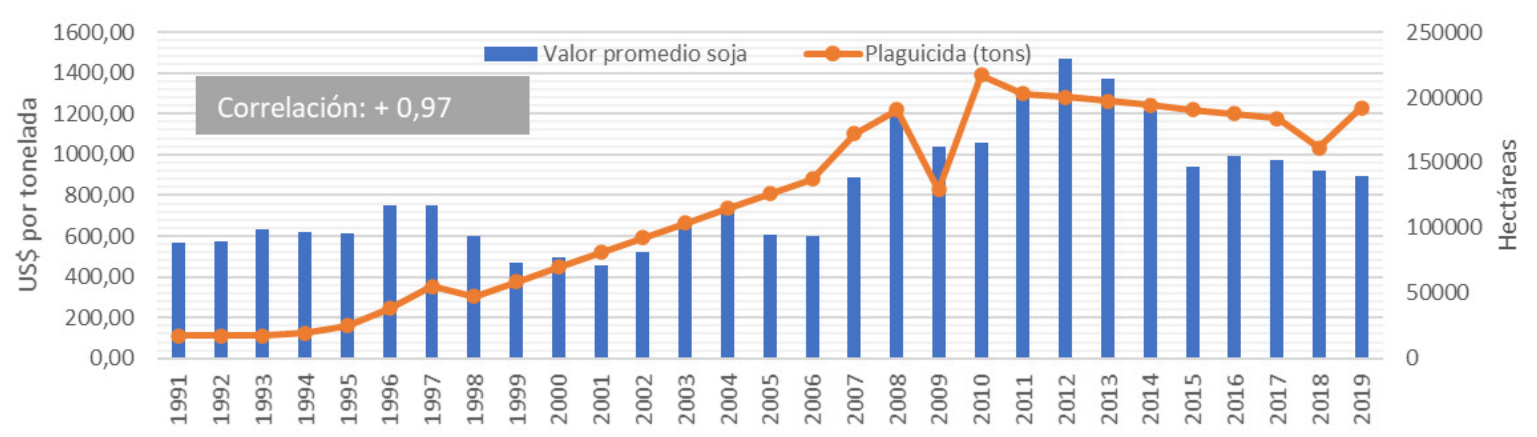

Fuente: Elaboración propia a partir de la combinación de datos disponibles el Ministerio de Agroindustria, Ganadería y Pesca (https://datos.agroindustria.gob.ar/) e Investing (https://es.investing.com/commodities/us-soybeans-historical-data).

Paralelamente con la profundización del consumo de glifosato, en varias localidades rurales (como Malvinas argentinas en la Provincia de Córdoba) se registraron residuos agrotóxicos en la población y aumentó el porcentaje de casos de cáncer. A su vez, se han encontrado altos niveles de glifosatos en zonas urbanas, hasta 20 veces superiores que en los campos de cultivo (Mac Loughlin et al., 2017). Por otro lado, en los últimos años investigaciones científicas locales han demostrado que el glifosato afecta el desarrollo neuronal de las personas, lo que aumenta considerablemente el riesgo de autismo y trastorno intelectual en niños (Coullery et al., 2016; Von Ehrenstein et al., 2019). Por lo tanto, para el Estado argentino, el glifosato se presentó simultáneamente como una oportunidad para profundizar el crecimiento económico tras la crisis y como una amenaza para su comunidad. La ausencia del Estado en la regulación de la producción de soja, ha sido funcional a la reproducción de este modelo.

\subsubsection{La endeble regulación corporativa en el campo nacional y las reacciones simbólicas en el campo público global}

A medida que se fueron haciendo cada vez más visible los efectos adversos del glifosato y sin una participación regulatoria del Estado nacional, se conformaron improvisadas alianzas en el campo nacional que buscaron detener los efectos nocivos de esta práctica. Una de las organizaciones pionera fue «Las madres de Ituzaingó» en el año 2002 en la provincia de Córdoba. Este grupo de mujeres reaccionaron frente al aumento de casos de cáncer en los vecinos del barrio. Diez años después, lograron llevar a juicio el caso, lo que lo convirtió en el primer antecedente legal en América Latina en búsqueda de frenar el avance de la agricultura con glifosato. Si bien la condena reconoció el delito incurrido por el productor agropecuario y un aerofumigador, las penas fueron excarcelables y no involucraron a la Corporación Monsanto ni la toxicidad de su producto (Aranda, 2012). Algo similar sucedió tanto en la provincia de Chaco en la localidad La Leonesa como en la Provincia de Santa Fe, cuando vecinos notaron casos crecientes de leucemia y contaminación de agua. Tiempo después, la justicia resolvió que las fumigaciones aéreas debían tener una distancia respecto de las viviendas (Aranda, 2011; Romig, 2010).

Progresivamente con los daños visibles, fueron emergiendo redes de médicos y otros profesionales que se opusieron al glifosato como consecuencia del creciente aumento de malformaciones de distintas poblaciones rurales (Pedemonte Castro, 2017, p. 36). Entre ellas se encuentra la Federación Argentina de Medicina General (FAMG), la Red Universitaria de Ambiente y Salud, Médicos de Pueblos Fumigados, la Red Federal de Docentes por la Vida, la RENAMA (Red Nacional de Municipios y Comunidades que Fomentan la Agroecología), y la FESPROSA (Federación Sindical de profesionales de la salud). A su vez, se creó una red de autoconvocados compuesta por vecinos que se llamó «paren de fumigarnos».

Frente a la presión local y sin legislación nacional que regule la actividad corporativa en Argentina, fueron las intendencias las instancias de reclamo y las que finalmente reglamentaron las fumigaciones. Esto fue resistido en muchos casos por las consecuencias económicas, en donde los productores fueron los principales defensores del uso del glifosato, hecho que acentúo el conflicto a nivel local (Cárdenas, 2018). Sin la voz oficial, el escenario se tornó una batalla entre productores agrarios que buscaron maximizar sus ganancias y 
GAPP. Nueva Época - N. ${ }^{2}$ 28, marzo 2022 - ISSN: 1989-8991 - DOI: https://doi.org/10.24965/gapp.i28.10931 - [Págs. 127-142]

El alcance de la Regulación Privada Transnacional: el caso de la multinacional Monsanto en Argentina

German Ezequiel Ricci

continuar con el histórico uso de plaguicidas, y la población vecina que comenzó a evidenciar las consecuencias del glifosato en la vida cotidiana. En un marco que no presenta jerarquías claras, el uso de este producto se tornó discutible y apelable, en un lapso de tiempo relativamente extenso, lo que perpetua el daño.

A partir del 2015, los reclamos se fueron direccionando cada vez más hacia la corporación. Surgieron nuevas organizaciones locales integradas por sanitaristas, investigadores, asambleas ambientales que iniciaron la campaña «si a la vida, no a Monsanto» (Corresponsal, 2015). A su vez, distintas ONG globales también presionaron a la corporación. La Vía Campesina, Combat Monsanto y Friends of the Earth Monsanto han elaborado informes y llevado a cabo campañas para visibilizar las consecuencias del uso extensivo del glifosato en la Argentina (Zacune, 2012).

Por otra parte, la ONG global AVAAZ se opuso localmente a la instalación de una planta industrial de Monsanto en la Provincia de Córdoba, en donde los casos de cáncer habían crecido considerablemente (Medrado Avila-Vazquez y Difilippo, 2016; Mozart, 2018). La corporación demandó a la ONG en la justicia argentina, hecho que marca los déficits de la RPT ya que el reclamo pudo ser inhibido momentáneamente, mientras perpetúa la actividad económica. Esto también evidencia que los canales tradicionales de reclamo del campo nacional no fueron suplantados por los nuevos espacios creados en la RPT, sino que coexisten.

En el campo público global quien ofició como árbitro y efectivamente condenó la actuación de Monsanto fue un tribunal internacional en La Haya en el año 2017. El Órgano no formal analizó la historia de multinacional y sentenció a la empresa culpable del delito de ecocidio, de crímenes de guerra, de violaciones a los derechos a un medio ambiente sano y equilibrado, a la salud y a la alimentación, y de quebrantar la libertad científica (Nodal, 2017; Via Campesina, 2016). Con estas conclusiones, se espera que los resultados sean utilizados en potenciales demandas con jurisdicción nacional. Si bien esto afecta la reputación de la corporación y efectivamente Monsanto es una de las corporaciones más desprestigiada, la sentencia no es vinculante, sino meramente declarativa. Esto da lugar a que la actividad de la corporación perpetúe. De hecho, la compra de la compañía por parte de Bayer en el 2016 permitió una «resiliencia reputacional» que garantizó la continuidad del glifosato (Cosentino, 2019).

Por último, las ONG que participaron de la alianza Global Compact en la que estaba inscripta Monsanto, no se pronunciaron con respecto al glifosato mientras que han reivindicado los programas de responsabilidad social implementados (UN Global Compact, 2018). Su escasa presencia en el campo local ha contribuido a la falta de visibilización de los daños en la población. Esta omisión comprueba la antes mencionada capacidad discrecional para seleccionar aliados con el propósito de legitimar a la corporación.

La experiencia de Monsanto en Argentina muestra que las organizaciones de la sociedad civil en el campo nacional que se conformaron para regular la actividad corporativa se vieron obligadas a desarrollar una expertise técnica para comprobar el propio daño de la actibidad corporativa. A la vez, como agentes espontáneos que pretendieron ejercer la regulación privada transnacional, debieron validarse como actores legítimos. Esta falta de legitimidad a priori permitió inicialmente que fueran fácilmente evadidos e ignorados por la corporación y el Estado nacional respectivamente. Si bien algunas investigaciones impulsadas por ONG locales lograron detener el avance de Monsanto y el uso extensivo de glifosato en algunas jurisdicciones, esto se dio en los casos que el daño era efectivamente comprobado. El caso argentino muestra que dentro de la RPT subyace una lógica que sostiene que el herbicida no es nocivo hasta que se demuestre lo contrario, y que quienes lo tienen que demostrar son sus víctimas. Fueron finalmente las instancias estatales que la RPT pretende olvidar, las que más avanzaron en la restricción de este producto. Particularmente las intendencias locales -las que no perciben ingresos directos por la exportación de soja- reglamentaron las fumigaciones (Cárdenas, 2018). Esto sucedió frente a un Estado nacional que necesariamente se encuentra en retraída en materia de regulación de la producción de soja para reproducir sus ingresos fiscales.

\subsubsection{De lo nacional a lo regional: Las coincidencias del Mercosur con el Estado-Nación argentino en la escasa regulación corporativa}

Otro de los actores que tiene potestad para legislar la actividad corporativa es el Mercosur. Este bloque de integración regional, poco avance ha tenido en la regulación del glifosato. En el año 1993, creó un marco para el desarrollo de normas fitosanitarias (conocido oficialmente como el Acuerdo Sanitario y Fitosanitario entre los Estados Partes del Mercosur N..$^{\circ}$ 06/93) pero recién 10 años después instó a que los países integrantes realicen la clasificación arancelaria del glifosato (Dictamen de Clasificación Arancelaria N. ${ }^{\circ}$ 05/03, 2003). A su vez, el Mercosur cuenta con el Comité de Sanidad Vegetal del Cono Sur (COSAVE) que es el or- 
ganismo de referencia regional en los trabajos de armonización de las reglamentaciones fitosanitarias, pero no ha producido avances en relación al glifosato. Recién en el año 2018, después de más de dos décadas de uso masivo de este herbicida, ingresó una Propuesta de recomendación en la que el PARLASUR solicitó al Consejo del Mercado Común (CMC) la implementación de un Acuerdo que unifique las reglamentaciones en materia de inocuidad de los alimentos y control sanitario de animales y vegetales, para todos los países del MERCOSUR (Fidel, 2018). En caso que este proyecto prospere, el mismo podría impactar sobre la regulación del glifosato, aunque no propone soluciones específicas para las problemáticas actuales por lo que no se prevén soluciones a corto plazo.

Desde sus inicios, esta organización supraestatal ha presentado pocos avances en la regulación de los negocios, reglas de origen, controles fitosanitarios y normas, y procedimientos técnicos. La falta de desarrollo responde a su bajo nivel de institucionalización. Algunos autores han demostrado que la naturaleza estado-centrista y la ausencia de interdependencia económica de sus miembros han impedido que los países desarrollen estrategias de comercio y regulación (Doctor, 2013). Esto ha mellado la posibilidad de generar una burocracia regional que regule las actividades económicas.

Desde que se profundizó el modelo sojero en Argentina, el Mercosur no ha sido una instancia recurrida por las organizaciones de la sociedad civil. El papel de estas dentro del Organismo es mínimo (Doctor, 2013, p. 528). Como se demostró más arriba, los reclamos siguieron siendo locales, en el campo nacional.

La falta de posicionamiento del Mercosur respecto al glifosato ha ausentado aún más la voz de los damnificados en el campo público global. Un alto nivel de desarrollo institucional con mayor legislación podría -en parte- contrarrestar el retiro de las instancias estatales en la regulación corporativa. Sin embargo, al analizar las implicancias económicas, esto no debe ser considerado como un déficit del Mercosur. Una fuerte regulación del glifosato por parte de esta instancia supraestatal implicaría cuestionar el neo-extractivismo que se ha implementado en la región, es decir, entorpecer el desarrollo de un modelo que funciona como fuente de divisas para los países latinoamericanos. En este sentido, tal como sucede a nivel nacional en Argentina, la falta de regulación por parte del Mercosur es una instancia complementaria de la reproducción del modelo reprimarizado basado en el consenso de los commodities.

\subsubsection{Los programas de responsabilidad social y el poder simbólico}

Los defensores de la RPT argumentan que los programas de responsabilidad social corporativa expresan el compromiso de la corporación con la comunidad y distribuyen políticas públicas que antes estaban en manos del Estado. En este apartado, se propone analizar las iniciativas de los programas de responsabilidad social de la Corporación Monsanto en Argentina e independientemente del alcance de estas políticas, se reflexiona sobre los efectos en el poder simbólico.

Monsanto ha desplegado numerosos programas de responsabilidad social a partir de la Fundación Monsanto en la región latinoamericana. Ha asumido como propia la responsabilidad de implementar políticas a grupos marginalizados. Amparándose en determinadas ONG locales, Monsanto destinó recursos económicos para apoyar sus objetivos. Algunas de las contribuciones podrían caracterizarse meramente como simbólicas ya que la destinación de recursos económicos ha sido escasa, sin ninguna posibilidad de revertir la situación de privación que padecen ciertos sectores. Estos han sido los casos de las iniciativas como «La Chocleada», «Familia CONIN», «Red de Bancos de Alimentos de Argentina», «AcercaRSE», «MOVILIZARSE», «La Fundación Leer» y el programa «Rincones de lectura», o «Monsanto Together» que se apoya en la actividad voluntaria de los vecinos.

Otros de los programas están relacionados con los temas por los cuales la corporación es batallada discursivamente. Este es el caso de las inversiones para pacientes hospitalizados y la limpieza del agua de distintas comunidades para garantizar el acceso a agua potable (Monsanto, 2017). Ambas iniciativas sirven para contrarrestar las acusaciones ligadas a los casos de cáncer y a la contaminación del agua por el uso extensivo de glifosato. En el mismo sentido, se encuentra el programa Revitamon que propuso la plantación de árboles para detener el efecto invernadero. El programa planeaba plantar 4.000 árboles en Argentina el 2016. Este número resulta insignificante si se tiene en cuenta que en Argentina se talaron en promedio alrededor de 900 millones de árboles por año (357.000 hectáreas de bosques nativos) entre 1998 y 2014 para expandir el cultivo de soja (Cacace y Molina, 2019, p. 5). Con los programas de responsabilidad social, Monsanto ha intentado contrarrestar los cuestionamientos que recibe en el espacio público Global y el impacto que este tiene en su credibilidad. 
Por otra parte, la Fundación Monsanto cuenta con otros programas populares con aportes económicos más significativos. Tal es el caso de "Semillero del Futuro» que data desde el 2005. Este programa apoyaba económicamente a instituciones sin fines de lucro que trabajen en comunidades rurales de menos de 100.000 habitantes, y financiaba proyectos que tengan impacto en la comunidad. Según la página oficial, el programa semilleros de Futuro invirtió hasta marzo del 2021, más de 5 millones de dólares en proyectos para la región latinoamericana (un promedio de US $\$ 335.000$ por año). A su vez, este programa ha priorizado determinadas problemáticas por sobre otras. Por ejemplo, en el 2018, Semilleros de futuro ha abierto la convocatoria para presentar proyectos orientados a mejorar la alimentación y nutrición en madres y niños de 0 a 5 años (Mesquida, 2018).

De menor alcance, se encuentra el programa «aprender+» en alianza con la Fundación Oficios que contribuye en las capacitaciones para la inserción laboral. El programa se ha desarrollado en varias localidades en Argentina, entre ellas Malvinas Argentinas, Ciudad de Córdoba, en Mendoza (con la Fundación CONIN), en el noroeste argentino y en el municipio de la Ciudad de Rojas, Provincia de Buenos Aires (Agosto, 2016, p. 116; Saadi, 2018, p. 26). Este último cuenta con 16.000 habitantes y los cursos tienen una duración de 4 meses y comprenden 20 alumnos. Suponiendo que los cursos se dicten todo el año, se trata de un programa que tiene un alcance anual menor al $0,4 \%$ de la población total.

A su vez, Monsanto también ha contribuido con la ONG estadounidense Junior Achievement para llevar a cabo un proyecto educativo destinado a niños de 13 a 15 años, con una orientación económica ligada a la actividad rural (Mercado, 2009). En el marco del retiro del Estado, este tipo de programas educativos orientados a la actividad de la corporación proponen un desarrollo productivo que desconoce otro tipo de desarrollos posibles. El programa educativo no solo implica la posibilidad de preparar la mano de obra del futuro ligada a la actividad corporativa, sino también imponer una cosmovisión de lo que debe ser el desarrollo económico-productivo de una localidad. Esto implica desarrollar legitimidad a la política económica corporativa. Por todo esto, el Estado argentino, históricamente cuestionado por su tamaño incompatible con sus ingresos y, por lo tanto, apremiado por llevar a cabo reformas o una reducción, encuentra en la Corporación la posibilidad de equilibrar parcialmente sus desbalances económicos al compartir el monopolio de la violencia simbólica en el campo educativo.

Si bien el alcance de estos programas es reducido, se deben tener en cuenta los riesgos que conlleva la ampliación de las funciones de responsabilidad social de las empresas. De extenderse estos programas en un contexto en el que el Estado participa cada vez menos en la implementación y regulación de determinadas actividades, las corporaciones contarán con un margen relativamente amplio para reproducir un modelo productivo ligado a la actividad corporativa.

Por otro lado, el poder político y económico de la corporación para el desarrollo de programas de responsabilidad social, condiciona las posibles decisiones futuras del gobierno en sus distintas instancias (nacional, provincial o municipal) ya que se dirigen a poblaciones ignoradas por él. Las inversiones destinadas a las comunidades de países con altos niveles de pobreza, por más mínimas y simbólicas, generan dependencia del Estado hacia la corporación. Asumiendo responsabilidades estatales, la corporación distribuye de manera arbitraria beneficios a comunidades marginalizadas. El surgimiento de una legislación que limite o perjudique económicamente a la corporación, no solo repercutirá en la actividad económica que esta se centra -sobre todo en los casos como el argentino donde la corporación y el Estado son socios estratégicos en la implementación de un modelo económico-, sino también puede tener consecuencia en el resto de las políticas públicas que fueron delegadas en la responsabilidad social corporativa.

En la responsabilidad social corporativa el Estado, al retraerse concede parcialmente la construcción de sentido a las corporaciones. En el marco de la RPT, el Estado sacrifica parcialmente su poder simbólico para reproducir su poder económico.

\section{CONCLUSIÓN}

El caso argentino evidencia la conjunción de endebles actores en la regulación del glifosato en el proceso de producción de soja, hecho que garantiza la extensión del modelo productivo en el campo nacional. Por un lado, se encuentran los actores que participan del emergente campo público global destinados a regular la actividad corporativa (como las organizaciones de la sociedad civil) que han sido ineficaces dada la asimétrica relación de poder dentro de este campo. Si bien la RPT sostiene que los actores de la sociedad civil están llamados a afectar la reputación y credibilidad de la Corporación, y efectivamente cuentan con 
esas facultades ya que el caso argentino así lo evidencia, se desconoce el poder de contestación, recuperación o transformación de la pérdida de capital simbólico, lo que permite perpetuar la actividad corporativa. La judicialización de las ONG, los programas de responsabilidad social y la venta de la compañía a Bayer respectivamente dan cuenta de esta estrategia. Por lo tanto, el espacio público global se consolida como un ámbito en el que cada temática es objeto de discusión y contestación, y esta falta de definiciones permite perpetuar el daño. En este sentido, se trata de un campo que es creíble y reconocido, pero no legítimo.

La falta de respuestas en el campo público global provocó que las principales víctimas del uso de glifosato finalmente recurran a las instancias tradicionales del campo nacional, como el poder judicial y las intendencias locales, que fueron las que lograron regular la actividad corporativa. Esto indica que el Estado Nación, en sus distintos niveles de administración pública aún conserva el monopolio de la violencia física y simbólica legitima. Sin embargo, se ha evidenciado que el uso de las facultades estatales resulta ex post, sobre daño consumado. Esta omisión a priori de la regulación corporativa responde a la necesidad económica y simbólica de reproducir el modelo sojero. Entre 1991 y 2017, el consumo de herbicidas estuvo fuertemente asociado al valor internacional del precio de la soja, lo que comprueba que la regulación del glifosato estuvo regida por el consenso de los commodities y no por las alianzas globales, tal como profesan los defensores de la RPT. En este marco, la ausencia del Estado argentino en la regulación corporativa y la falta de institucionalización del Mercosur obedece a los ingresos que se obtienen de esta actividad, que son estratégicos para la estructura económica primarizada. Los gobiernos y las corporaciones son aliados en la explotación de los recursos, pendientes de la obtención de divisas para cumplir con sus obligaciones financieras. Este modelo productivo basado -circunstancialmente- en la producción intensiva de soja explica la falta de objetivos ambientales y cuidados sanitarios.

Por último, debe considerarse la responsabilidad social corporativa que, si bien en la mayoría de los casos presenta un alcance limitado, esta práctica conlleva aspectos simbólicos. Sobre estas, las corporaciones se presentan libradas de toda obligación, lo que les permite introducirse en el campo público global y en el campo nacional como actores con una decisión voluntaria y altruista, que no necesita de ninguna atadura formal para mantener la conciencia social. Su colaboración se ampara puramente en una cuestión ética, ya que todo aquello que hacen podrían no hacerlo. Esta estrategia legitima a la Corporación al retroalimentar su poder simbólico. A su vez, la «beneficencia» de la corporación, carece de toda responsabilidad formal por lo que no hay un canal oficial que le permita a la comunidad exigirles. Por otra parte, la discrecionalidad de la que parte la responsabilidad corporativa, le permite a la corporación diseñar programas ajustados a su actividad económica. Esto contribuye a reproducir su poder simbólico, al promover y definir una cosmovisión del modelo productivo de una localidad, que legitima la propia actividad de la corporación.

Por todo esto se sostiene que, en el marco de la RPT, el Estado Nacional argentino con sus crisis económicas recurrentes pone en juego parte de su capital simbólico, para reproducir su capital económico, que en parte es necesario para mantener su capital simbólico. Es decir, el Estado, sin ceder el monopolio de la violencia física, habilita la construcción de sentido (o violencia simbólica) a la corporación porque precisa de esta para maximizar el ingreso de divisas y hacer frente a las obligaciones financieras, tanto en el campo nacional y en el campo internacional.

\section{REFERENCIAS BIBLIOGRÁFICAS}

Agosto, P. (2016). Un pueblo en lucha contra Monsanto en Córdoba, Argentina. Ecología Política, 51, 114-117. http:// www.jstor.org/stable/24894082

AFP (28 de marzo de 2019). Nueva condena a Monsanto por no advertir de que su herbicida puede producir cáncer. El País. https://elpais.com/sociedad/2019/03/28/actualidad/1553773460_982217.html

Aizen, M. A., Garibaldi, L. A. y Dondo, M. B. (2009). Expansión de la soja y diversidad de la agricultura argentina. Ecología austral, 19(1), 45-54. http://ojs.ecologiaaustral.com.ar/index.php/Ecologia_Austral/article/view/1367

Alberada Vivó, L. (2009). La contribución de las autoridades privadas a la gobernanza global: Las élites empresariales en las iniciativas de responsabilidad social de la empresa [Tesis doctoral]. Universitat Autónoma de Barcelona. https://www.tdx.cat/handle/10803/5243\#page=1

Aranda, D. (2011, 18 de marzo). Primero la salud, después los negocios. Página 12. https://www.pagina12.com.ar/ diario/sociedad/3-164438-2011-03-18.html

Aranda, D. (2012, 22 de agosto). Juicio por agrotóxicos en Ituzaingó: fumigar es delito, pero no hubo cárcel. Lavaca. https://www.lavaca.org/notas/juicio-por-agrotoxicos-en-ituzaingo-culpa-sin-carcel/ 
GAPP. Nueva Época - N. ${ }^{2}$ 28, marzo 2022 - ISSN: 1989-8991 - DOI: https://doi.org/10.24965/gapp.i28.10931 - [Págs. 127-142]

El alcance de la Regulación Privada Transnacional: el caso de la multinacional Monsanto en Argentina

German Ezequiel Ricci

Argüelles Ramos, L. (2020, 23 de julio). ¿Se acerca el fin del Glifosato en Europa? The Conversation. https:// theconversation.com/se-acerca-el-fin-del-glifosato-en-europa-141751

Bauman, Z. (2015). Modernidad líquida. Fondo de cultura económica.

Bell, S. y Hindmoor, A. (2009). Rethinking governance: The centrality of the state in modern society. Cambridge University Press. https://doi.org/10.1017/CBO9780511814617

Bexell, M., Tallberg, J. y Uhlin, A. (2010). Democracy in Global Governance: The Promises and Pitfalls of Transnational Actors. Global Governance: A Review of Multilateralism and International Organizations, 16(1), 81-101. https://doi. org/10.1163/19426720-01601006

Bianchi, E. y Szpak, C. (2017). Soybean prices, economic growth and poverty in Argentina and Brazil. Soybean prices, economic growth and poverty in Argentina and Brazil. Organización de las Naciones Unidas para la Agricultura y la Alimentación (FAO). https://www.fao.org/3/l8316EN/i8316en.pdf

Bourdieu, P. (2006). Sobre el poder simbólico. En P. Bourdieu, Intelectuales, política y poder (pp. 65-73). Eudeba.

Bourdieu, P. (2015). Sobre el Estado. Cursos en el College France 1989-1992. Fondo de Cultura Económica.

Bourdieu, P. y Passeron, J. C. (2001). Fundamentos de una teoría de la violencia simbólica. En La Reproducción. Elementos para una teoría del sistema de enseñanza (pp. 15-85). Popular.

Bravo, E. y Naranjo, A. (2016). América Latina fumigada y crisis de las commodities: el caso del glifosato de Monsanto. Ciencia política, 11(21), 229-250. https://doi.org/10.15446/cp.v11n21.60295

Burger, L. y Bellon, T. (2020, 24 de junio). Bayer to pay up to $\$ 10.9$ billion to settle bulk of Roundup weedkiller cancer lawsuits. Reuters. https://www.reuters.com/article/us-bayer-litigation-settlement/bayer-to-pay-up-to-10-9-billion-tosettle-bulk-of-roundup-weedkiller-cancer-lawsuits-idUSKBN23V2NP

Cacace, G. P. y Morina, J. O. (2019, 11 de octubre). Expansión de la soja transgénica y deforestación en la Argentina, 1990-2018. VII Congreso Nacional de Geografía de Universidades Públicas y XXI Jornadas de Geografía de la UNLP. http://jornadasgeografia.fahce.unlp.edu.ar/front-page/actas/ponencias/Cacace.pdf

Cafaggi, F. (2014). Los nuevos fundamentos de la Regulación Privada Transnacional. Revista Derecho Privado, 26, 185-217. https://revistas.uexternado.edu.co/index.php/derpri/article/view/3799

Cárdenas, S. (2018, 13 de agosto). ¿Qué países usan y prohíben el glifosato en el mundo? El Colombiano. https:// www.elcolombiano.com/internacional/el-mapa-del-uso-y-prohibicion-del-glifosato-en-el-mundo-NX9154528

Corresponsal (2015, 27 de mayo). Campaña Nacional: Sí a la Vida. No al Glifosato. Alternativa Socialista. https:// as.mst.org.ar/2015/05/27/campana-nacional-si-la-vida-al-glifosato/

Cosentino, S. M. (2019). Los desafíos de una empresa con mala reputación frente a la Opinión Pública: análisis del caso Monsanto [Tesis doctoral]. Universidad del Salvador. http://cosechador.siu.edu.ar/bdu3/Record/USALR-oai:racimo.usal.edu.ar:6526

Coullery, R. P., Ferrari, M. E. y Rosso, S. B. (2016). Neuronal development and axon growth are altered by glyphosate through a WNT non-canonical signaling pathway. Neurotoxicology, 52, 150-161. http://dx.doi.org/10.1016/j. neuro.2015.12.004

Cutler, A. C. (2003). Private power and global authority: transnational merchant law in the global political economy. Cambridge: Cambridge University Press, 90, 1-292. http://dx.doi.org/10.1017/CBO9780511550300

Dictamen de Clasificación Arancelaria N. ${ }^{\circ} 05 / 03$ (2003, 18 de julio). MERCOSUR/CCM/DIR. N. ${ }^{\circ}$ 05/03. INFOLEG N. ${ }^{\circ}$ 420.552. http://servicios.infoleg.gob.ar/infoleglnternet/anexos/85000-89999/86898/norma.htm

Doctor, M. (2013). Prospects for deepening Mercosur integration: Economic asymmetry and institutional deficits. Review of International Political Economy, 20(3), 515-540. http://dx.doi.org/10.1080/09692290.2012.671763

EI País (2017, 28 de noviembre). La UE autoriza el glifosato por otros cinco años. https://elpais.com/ internacional/2017/11/27/actualidad/1511794192_322345.html

Falkner, R. (2003). Private environmental governance and international relations: exploring the links. Global environmental politics, 3(2), 72-87. https://doi.org/10.1162/152638003322068227

Fidel, G. (2018, 3 de agosto). Propuesta de recomendación del Parlamento del MERCOSUR al Consejo del Mercado Común para implementar un Acuerdo General de Normas Sanitarias y Fitosanitarias que coadyuve a establecer un Estatus Fitosanitario Común e Integrado en el MERCOSUR y extensivo a otros países de la región en lo que se refiere a la producción, inspección, muestreo, ensayos, importación, traslado y certificación del material vegetal. Parlamento del Mercosur. https://www.parlamentomercosur.org/innovaportal/file/15584/1/2018.08.03proyecto-barreras-fitosanitarias.pdf

Giraudo, M. E. (2021). Taxing the «crop of the century»: the role of institutions in governing the soy boom in South America. Globalizations, 18(4), 516-532. https://doi.org/10.1080/14747731.2020.1795426

Graz, J. C. y Nölke, A. (2012). The limits of transnational private governance. The Diffusion of Power in Global Governance (pp. 118-140). Palgrave Macmillan.

Grugel, J. y Riggirozzi, P. (2012). Post-neoliberalism in Latin America: Rebuilding and reclaiming the state after crisis. Development and Change, 43(1), 1-21. https://doi.org/10.1111/j.1467-7660.2011.01746.x

Mac Loughlin, T. M., De Castro, M. C., López Aca, V., Orofino, A., Davidovich, I., Bernasconi, C. y Marino, D. (2017, septiembre). La química ambiental como herramienta de transformación social: glifosato en espacios públicos urbanos y propuestas para su prohibición [Presentación de póster]. XIV Congreso Internacional Científico y Tecnológico-CONCYT. https://digital.cic.gba.gob.ar/handle/11746/6788 
GAPP. Nueva Época - N. ${ }^{2}$ 28, marzo 2022 - ISSN: 1989-8991 - DOI: https://doi.org/10.24965/gapp.i28.10931 - [Págs. 127-142]

El alcance de la Regulación Privada Transnacional: el caso de la multinacional Monsanto en Argentina

German Ezequiel Ricci

Medrado Avila-Vazquez, M. y Difilippo, F. (2016). Agricultura tóxica y salud en pueblos fumigados de Argentina. Revista de conflictos sociales latinoamericanos, 2, 23-45. https://www.criticayresistencias.com.ar/revista/article/view/70

Menéndez, C. (2020, 4 de febrero). Luxemburgo abre camino en la prohibición del glifosato en la Unión Europea. Euronews. https://es.euronews.com/2020/02/04/luxemburgo-abre-camino-en-la-prohibicion-del-glifosato-en-launion-europea

Mercado (2009, 4 de septiembre de). «Nuestro campo», la inciativa de Junior Achievement y Monsanto. https:// mercado.com.ar/protagonistas/nuestro-campo-la-inciativa-de-junior-achievement-y-monsanto/

Mesquida, F. (2018, 1 de febrero). Fundación Monsanto lanzó la nueva edición del programa Semillero de Futuro. Infocampo. https://www.infocampo.com.ar/fundacion-monsanto-lanzo-la-nueva-edicion-del-programa-semillero-defuturo/

Monsanto (2017, diciembre). Growing better together. 2017 Sustainability report. https://www.monsanto.com/app/ uploads/2017/12/Sustainability 2017.pdf

Montenegro, R. (2012). Monsanto amenaza Malvinas Argentinas: semillas envenenadas y pérdida de soberanía alimentaria [Tesis Doctoral]. Funam. https://www.unrc.edu.ar/unrc/ocsa/docs/m-extractivista/monsantopormontenegro.pdf

Montenegro, C., Strada, M., Bono, J., Gasparri, I., Manghi, E., Parmuchi, E. y Brouver, M. (2005). Estimación de la pérdida de superficie de bosque nativo y tasa de deforestación en el norte de argentina [Presentación en Congreso]. UMSEF. https://www.researchgate.net/profile/Nestor-Gasparri/publication/323548055_Estimacion_ de_la_perdida_de_superficie_de_bosque_nativo_y_tasa_de_deforestacion_en_el_norte_de_argentinal linkss/5aa29db40f7e9badd9a664ae/Estimacion-de-la-perdida-de-superficie-de-bosque-nativo-y-tasa-dedeforestacion-en-el-norte-de-argentina.pdf

Mozart, M. (2018, 31 de agosto). Monsanto lleva a juicio a plataforma Avaaz y quiere datos privados de millones de usuarios. La Red 21. http://www.Ir21.com.uy/ecologia/1378639-monsanto-demanda-avaaz

Newell, P. (2008). The political economy of global environmental governance. Review of International Studies, 34(3), 507-529. https://doi.org/10.1017/S0260210508008140

Nodal (2017, 20 de abril). Tribunal simbólico en La Haya condena a Monsanto por crímenes de guerra y ecocidio. https://www.nodal.am/2017/04/simulacro-juicio-la-haya-encuentra-monsanto-culpable-crimenes-guerra-ecocidio/

Noticiauno (2020, 5 de junio). Argentina lidera el ranking mundial por la cantidad de glifosato que usa el campo. http:// www.noticiauno.com.ar/nota/3502-Argentina-lidera-el-ranking-mundial-por-la-cantidad-de-glifosato-que-usa-el-campo

Organización de las Naciones Unidas para la Agricultura y la Alimentación (FAO) (2004). Uso de fertilizantes por cultivo en Argentina. https://www.fao.org/publications/card/es/c/164b9eec-c74d-5924-bf40-974dcfe773f8/

Pedemonte Castro, F. E. (2017). Problemática del uso de glifosato [Tesis Monográfica]. Universidad Agraria La Molina. https://hdl.handle.net/20.500.12996/3011

RALLT (2015, 11 de diciembre). Un mal cabalga con el viento, la toxicidad y carcinogenicidad del glifosato. Biodiversidad La. https://www.biodiversidadla.org/Documentos/Un_mal_cabalga_con_el_viento._La_toxicidad_y_ carcinogenicidad_del_glifosato

Rapoport, M. (2010). Las políticas económicas de la Argentina: una breve historia. Planeta.

RFI (2019, 10 de diciembre). Francia retirará del mercado 36 productos a base de glifosato. France 24. https://www. france24.com/es/20191210-agencia-francia-seguridad-salud-retira-mercado-productos-glifosato

Romig, S. (2010, 17 de marzo). Argentina Court Blocks Agrochemical Spraying Near Rural Town. Dow Jones News. http://ih.advfn.com/stock-market/NYSE/monsanto-MON/stock-news/42014713/argentina-court-blocksagrochemical-spraying-near

Rosenau, J. y Czempiel, E. (eds.) (1992). Governance without Government: Order and Change in World Politics. Cambridge University Press. http://doi.org/10.1017/CBO9780511521775

Rossi, G. D. (2013). La volatilidad en mercados financieros y de commodities: Un repaso de sus causas y la evidencia reciente. Invenio, 16(30), 59-74. Recuperado de https://www.redalyc.org/pdf/877/87726343005.pdf

Ruggie, J. G. (2004). Reconstituting the global public domain: issues, actors, and practices. European journal of international relations, 10(4), 499-531. https://doi.org/10.1177\%2F1354066104047847

Saadi, C. (2018). Las Relaciones Públicas como herramienta de Responsabilidad Social Empresarial. Propuesta de intervención para el programa «Aprender+» de la planta María Eugenia de Monsanto en la localidad de Rojas [Tesis]. Universidad Abierta Interamericana. http://imgbiblio.vaneduc.edu.ar/fulltext/files/TC128417.pdf

Svampa, M. (2013). Consenso de los Commodities y lenguajes de valoración en América Latina. Nueva Sociedad, 244, 30-46. https://www.nuso.org/articulo/consenso-de-los-commodities-y-lenguajes-de-valoracion-en-america-latina/

Svampa, M. (2018). Continuidad y radicalización del neoextractivismo en Argentina. Perfiles Económicos, 3, $87-97$. https://doi.org/10.22370/rpe.2017.3.1222

Teubal, M. (2003). Soja transgénica y crisis del modelo agroalimentario argentino. Realidad Económica, 196, 52-74. https://www.unida.org.ar/Virtuales/Problemas\%20Ambientales/M3/Soja\%20transgenica $\% 20 \mathrm{y} \% 20 \mathrm{crisis} \% 20$ modelo\%20agroalimentario.pdf

Teubal, M., Reveles, I. L. A., Lindenboim, J., Giarracca, N., Gomez, M., Díaz, P. y Trombetta, M. (2008). Soja y agronegocios en la Argentina: la crisis del modelo. Lavboratorio, 10(22), 5-7. Recuperado de http://biblioteca. clacso.edu.ar/Argentina/iigg-uba/20120626030815/lavbo22.pdf 
United Nations Global Compact (11 de mayo de 2018). Growing Better Together 2017 Communication on Progress. https://www.unglobalcompact.org/participation/report/cop/create-and-submit/active/417671

Via Campesina (2011, 19 de diciembre). Argentina: Histórica Movilización Campesina Indígena contra el agronegocio. https://viacampesina.org/es/argentina-historica-movilizacion-campesina-indigena-contra-el-agronegocio/

Via Campesina (2016, 13 de julio). Tribunal contra Monsanto en La Haya. https://viacampesina.org/es/tribunal-contramonsanto-en-la-haya/

Von Ehrenstein, O. S., Ling, C., Cui, X., Cockburn, M., Park, A. S., Yu, F. y Ritz, B. (2019). Prenatal and infant exposure to ambient pesticides and autism spectrum disorder in children: population based case-control study. Bmj Clinical Research ed, 364, 1-10. https://doi.org/10.1136/bmj.1962

Zacune, J. (2012). Lucha contra Monsanto. Resistencia de los movimientos de base al poder empresarial del agronegocio en la era de la "economía verde» y un clima cambiante. Amigos de la Tierra Internacional, La Vía Campesina, Combat Monsanto. https://viacampesina.org/es/wp-content/uploads/sites/3/2012/04/MonsantoPublication-ES-Final-Version-1.pdf

Zarrilli, A. G. (2016). Ambiente, producción y mercado. El impacto transformador en una economía periférica, el Gran Chaco Argentino en el siglo XX. Áreas. Revista Internacional de Ciencias Sociales, 35, 121-139. https://revistas. um.es/areas/article/view/279191 